\title{
Estudo de validação comparativo entre as técnicas ELISA e RIFI para diagnosticar Leishmania sp em cães errantes apreendidos no município de Campos dos Goytacazes, Estado do Rio de Janeiro
}

\author{
Comparative validation study between the ELISA and RIFI techniques \\ for diagnosing Leishmania sp in stray dogs caught in the \\ municipality of Campos de Goytacazes, State of Rio de Janeiro
}

\author{
Mariane Pinto Fernandes Távora ${ }^{1}$, Maria Angélica Vieira da Costa Pereira ${ }^{2}$, \\ Valmir Laurentino Silva ${ }^{3}$ e Gilmar Ferreira Vita ${ }^{4}$
}

\begin{abstract}
RESUMO
Foi realizada uma pesquisa objetivando-se verificar a eficácia do teste ELISA, para detecção de anticorpos contra Leishmania sp em cães, comparando-o com o RIFI, padrão em humanos, e investigar a situação sorológica desta zoonose na microrregião. Os testes tiveram uma concordância de $97,6 \%$, classificada como forte.
\end{abstract}

Palavras-chaves: Leishmaniose. Cães. Sorologia. Zoonose. RIFI. ELISA.

\section{ABSTRACT}

A survey was carried out aiming to verify the ELISA test effectiveness for detecting antibodies against Leishmania sp in dogs, comparing with RIFI human pattern and for investigating sorological zoonosis situation in the microregion. An accordance about $97.6 \%$ considered strong was reported.

Key-words: Leishmaniosis. Dogs. Serology. Zoonosis. RIFI. ELISA.

A leishmaniose é uma doença causada por protozoário da ordem Kinetoplastida, família Trypanosomatidae e gênero Leishmania Ross, $1903^{6}$. 0 teste padrão ouro mundialmente indicado como comprovação final no diagnóstico da ocorrência ou não de anticorpos de Leishmania sp no homem é a reação de imunofluorescência indireta (RIFI). 0 ELISA (Enzyme Linked Immunossorbent Assay) é utilizado principalmente para detecção de anticorpos, quando se deseja realizar um levantamento soroepidemiológico prático, menos oneroso e rápido. É sabido que a RIFI apresenta maior grau de especificidade e que o ELISA apresenta maior grau de sensibilidade ${ }^{2}$. O objetivo deste trabalho foi verificar a eficácia do teste ELISA para detecção de anticorpos contra Leishmania sp em cães, comparandoo à RIFI, padrão em humanos, e investigar a situação sorológica desta zoonose no município de Campos dos Goytacazes, RJ, no período de dezembro de 2000 a dezembro de 2001.

Foram selecionados 370 cães errantes, adultos, mestiços, apreendidos no município. As amostras sangüíneas $(5 \mathrm{ml})$ foram obtidas sem anticoagulante e centrifugadas, separando-se o soro, que foi armazenado sob congelamento $\left(-20^{\circ} \mathrm{C}\right)$ em duas cotas (tubos de microcentrífuga estéreis para cada amostra).

o ELISA para leishmaniose canina (complexo Leishmania donovani), consiste em um teste elaborado por Avrameas e cols, em 1992, e modificado por Laurentino-Silva 33 (kit Bio-Manguinhos/FIOCRUZ), onde o resultado é obtido através da visualização da alteração de cor sem 0 auxílio de equipamentos mensuradores de absorbância. Neste teste utilizou-se uma titulação variando entre 1:40 a 1:807.

\footnotetext{
1. Fundação Estadual Norte Fluminense/Parque de Alta Tecnologia do Norte Fluminense, Campos dos Goytacazes, RJ. 2. Setor de Parasitologia, Hospital Veterinário, Centro de Ciências e Tecnologias Agropecuárias, Universidade Estadual do Norte Fluminense Darcy Ribeiro, Campos dos Goytacazes, RJ. 3. Laboratório de Imunodiagnóstico, Departamento de Ciências Biológicas, Escola Nacional de Saúde Pública, Fundação Instituto Oswaldo Cruz, Rio de Janeiro, RJ. 4. Universidade Castelo Branco, Rio de Janeiro, RJ. Trabalho financiado pela Fundação Carlos Chagas Filho de Amparo à Pesquisa do Estado do Rio de Janeiro.

Endereço para correspondência: Dra. Maria Angélica Vieira da Costa Pereira. Setor de Parasitologia/Hospital Veterinário/CCTA/UENF. Av. Alberto Lamego 2000, Parque Califórnia, 28013-600 Campos dos Goytacazes, RJ.

Tel: 5522 2726-1500 ramal 1701-1702

e-mail: angel@uenf.br

Recebido em: 06/09/2006

Aceito em: 27/04/2007
} 
A reação de imunofluorescência indireta para leishmaniose humana (complexo Leishmania major like), é o teste padrão ouro de referência para diagnóstico humano, segundo Coons e cols. (1941), citado por Laurentino-Silva 3 (kit Bio-Manguinhos/FIOCRUZ), e também muito utilizado em Medicina Veterinária para diagnóstico da leishmaniose canina. A titulação de 1:40 a 1:80 foi estabelecida como padrão também para o diagnóstico da RIFI?

Os resultados dos testes sorológicos foram confrontados para a verificação da co-positividade, co-negatividade e concordância bruta. Estes parâmetros foram obtidos em função da distribuição dos resultados dos testes sorológicos ${ }^{3}$.

A fórmula equacional, utilizada para o cálculo da co-positividade, co-negatividade e o índice de concordância bruta, encontra-se visualizada na Tabela 1 .

Tabela 1 - Cálculos de concordância.

\begin{tabular}{lccc}
\hline Teste $2^{* * *}$ & \multicolumn{2}{c}{ Teste 1 (teste de referência)* } & \\
\cline { 2 - 3 } & positivo & negativo & Total \\
\hline Positivo & $\mathrm{A}$ & $\mathrm{B}$ & $\mathrm{a}+\mathrm{b}$ \\
Negativo & $\mathrm{C}$ & $\mathrm{D}$ & $\mathrm{c}+\mathrm{d}$ \\
\hline Total & $\mathrm{a}+\mathrm{c}$ & $\mathrm{b}+\mathrm{d}$ & $\mathrm{a}+\mathrm{b}+\mathrm{c}+\mathrm{d}$ \\
\hline
\end{tabular}

* Reação de Imunofluorescência Indireta (RIFI).

** Enzyme Linked Immunossorbent Assay (ELISA).

Calcula-se para RIFI/ELISA: co-positividade $=\mathrm{a} \div(\mathrm{a}+\mathrm{c})$; co-negatividade $=d \div(b+d)$ e concordância bruta $=(a+d) \div(a+b+c+d)$.

Calcula-se para ELISA/RIFI: co-positividade $=\mathrm{a} \div(\mathrm{a}+\mathrm{b})$; co-negatividade $=\mathrm{d} \div(\mathrm{c}+\mathrm{d})$ e concordância bruta $=(a+d) \div(a+b+c+d)$.

Utilizou-se o seguinte critério para conceituar os resultados do controle de qualidade em relação à concordância: valores $\leq 40 \%$ são considerados pobres, de 40,1 até 79,9\% regulares, de 80 a $89,9 \%$ são considerados bons e $\geq 90 \%$ consideram-se como excelentes 3 .

A análise dos resultados obtidos nas duas técnicas de diagnóstico foi realizada pelo teste de coeficiente de Kappa $(k)^{1}$.

Das 370 amostras de soros coletadas, 6 (1,6\%) foram positivas e 355 (95,9\%) negativas para ambos os testes, 2 (0,5\%) obtiveram positividade para RIFI e negatividade para ELISA e 7 (1,9\%) negatividade para RIFI e positividade para ELISA.

A relação de co-positividade ELISA/RIFI foi de 46,2\%, e a de conegatividade ELISA/RIFI foi de 99,4\%; a co-positividade RIFI/ELISA foi de $75 \%$ e a co-negatividade RIFI/ELISA foi de 98,1\%. Através destes resultados pode-se realizar o teste estatístico do coeficiente de Kappa, para avaliar a concordância entre as duas técnicas diagnósticas, onde se verificou uma concordância observada de $97,6 \%$ e esperada 94,5\%, altamente significativa $(\mathrm{p}<0,01)$ entre os resultados positivos e negativos, sendo esta concordância classificada como forte $(0,8 \leq \mathrm{k}<1)$.

A associação dos dois testes fez-se necessária no presente trabalho para testar a eficácia do ELISA para leishmaniose canina, kit
Bio-Manguinhos/FIOCRUZ ${ }^{3}$, que vem a ser um ELISA modificado em que os resultados são obtidos sem haver necessidade da leitura em espectofotômetro, e a simples alteração de cor indica a positividade (amarelo) ou negatividade (incolor) da amostra a ser testada. Os resultados obtidos desta forma diminuem os custos operacionais do diagnóstico e por apresentar esta praticidade pode ser utilizado a campo 5 .

A reação de imunofluorescência indireta é diagnóstico padrão para leishmaniose tegumentar americana em humanos e foi também utilizada como técnica de diagnóstico sorológico em cães de áreas endêmicas do Rio de Janeiro ${ }^{7}$. Até então, não se utilizava o teste sorológico em cães, sendo o diagnóstico realizado por intradermorreação.

A reação de imunofluorescência indireta é um bom teste confirmatório, podendo ser utilizado como contraprova do ELISA e este é um bom teste para triagem (screening-test). Nos casos de sorologia positiva, é indicado o sacrifício do animal ${ }^{4}$. Recomenda-se a associação dos dois testes em casos positivos no ELISA. Os dois testes apresentam fundamentos distintos e neste trabalho um excelente índice de co-positividade.

0 teste sorológico ELISA para leishmaniose canina é um bom teste para ser utilizado a campo em triagens soroepidemiológicas (campanhas de vacinação anti-rábica), devido à sua praticidade $\mathrm{e}$ baixo custo, o que é preconizado pela Organização Internacional de Epizootias $\left(\mathrm{OIE}^{5}\right)$. A eficácia do teste ELISA é comprovada através da concordância encontrada no valor de $97,6 \%$, conceituando o resultado como excelente. 0 teste sorológico RIFI padrão para humanos, como já foi descrito na literatura, é apropriado para confirmação sorológica, em casos de dúvida, ou como contraprova de casos positivos, em que, segundo o Ministério da Saúde, é necessário o sacrifício do animal.

\section{REFERÊNCIAS}

1. Arango HG. Bioestatística Teórica e Computacional. Guanabara Koogan SA, Rio de Janeiro, 2001.

2. Fundação Nacional de Saúde. Manual de Leishmaniose. Doenças Parasitárias. Ministério da Saúde, Rio de Janeiro, 2002.

3. Laurentino-Silva V. Imunologia aviária e aplicação da imunoglobulina Y (IgY) na soroepidemiologia das leishmanioses caninas. Tese de Doutorado, Universidade Federal Rural do Rio de Janeiro, Seropédica, RJ, 1999.

4. Ministério da Saúde. Controle, Diagnóstico e Tratamento da Leishmaniose Visceral. Fundação Nacional de Saúde, Brasília, 1994

5. Organização Internacional de Epizootias. Leishmaniosis in World. OIE, Paris, 2003.

6. Rey L. Parasitologia. Editora Guanabara Koogan, Rio de Janeiro, 1991.

7. Távora MPF. Inquérito sorológico para Leishmania sp em cães de rua apreendidos no município de Campos dos Goytacazes, estado do Rio de Janeiro. Tese de Mestrado, Universidade Estadual do Norte Fluminense Darcy Ribeiro, Campos dos Goytacazes, RJ, 2004. 